\title{
Simulation Analysis and Verification of Temperature and Stress of Wheel-Mounted Brake Disc of a High- Speed Train
}

Junsheng Qu ( $\nabla 17116350 @ b j t u . e d u . c n)$

Beijing Jiaotong University https://orcid.org/0000-0002-5195-6331

Wenjing Wang

Beijing Jiaotong University

Ziyu Dong

Beijing Jiaotong University

Original Article

Keywords: braking process, heat energy, friction surfaces, brake disc

Posted Date: September 21st, 2020

DOI: https://doi.org/10.21203/rs.3.rs-64105/v1

License: (c) (i) This work is licensed under a Creative Commons Attribution 4.0 International License.

Read Full License 


\section{Title page}

\section{Simulation Analysis and Verification of Temperature and Stress of Wheel-Mounted Brake Disc of a High-Speed Train}

Junsheng Qu, born in 1995, is currently a PhD candidate at School of Mechanical, Electronic and Control Engineering, Beijing Jiaotong University, China. He received his bachelor degree from Beijing Jiaotong University, China, in 2017. His research interests include safe operation of carrier tools and the structural strength.

E-mail: 17116350@bjtu.edu.cn

Wenjing Wang, born in 1976, is currently a professor at School of Mechanical, Electronic and Control Engineering, Beijing Jiaotong University, China. She received her PhD degree from Beijing Jiaotong University, China, in 2004. Her research interests include safe operation of carrier tools, safety detection and control of carrier tools and the structural strength.

E-mail: wjwang@bjtu.edu.cn

Ziyu Dong, born in 1997, is currently a PhD candidate at School of Mechanical, Electronic and Control Engineering, Beijing Jiaotong University, China. She received her bachelor degree from Beijing University of Civil Engineering and Architecture, China, in 2019. Her research interests include safe operation of carrier tools and the structural strength.

E-mail: 19121396@bjtu.edu.cn

\section{Corresponding author: Junsheng Qu E-mail: 17116350@bjtu.edu.cn}




\title{
Simulation Analysis and Verification of Temperature and Stress of Wheel-Mounted Brake Disc of a High-Speed Train
}

\author{
Junsheng $\mathrm{Qu}^{1} \cdot$ Wenjing Wang $^{1} \cdot$ Ziyu Dong ${ }^{1}$
}

\begin{abstract}
During the braking process, a large amount of heat energy is generated at the friction surfaces between the brake disc and pads and rapidly dissipates into the disc volume. In this paper, a three-dimensional thermo-mechanical coupling model of high-speed wheel-mounted brake discs containing bolted joints and contact relationships is established. The direct coupling method is used to analyse the temperature and stress of the brake discs during an emergency braking event with an initial speed of $300 \mathrm{~km} / \mathrm{h}$. A full-scale bench test is also conducted to monitor the temperatures of the friction ring and bolted joints. The simulation result shows that the surface temperature of the friction ring reaches its peak value of $413.7^{\circ} \mathrm{C}$ after $102 \mathrm{~s}$ of braking, which agrees well with the bench test result. The maximum alternating thermal stress occurs in the bolt hole where the maximum circumferential compressive stress is $-658 \mathrm{MPa}$ and the maximum circumferential tensile stress is $134 \mathrm{MPa}$. During the braking process, the out-of-plane deformation of the middle part of the friction ring is larger than that of the edge, which increases the axial tensile load of the connecting bolt. This work provides support for the design of brake discs and connecting bolts.
\end{abstract}

Keywords: High speed train; Wheel-mounted brake disc; Temperature field, Stress field; Thermo-mechanical coupling model; Bolt

\section{Introduction}

Compared with other braking methods, disc brakes have the advantages of simple structure and reliability, which plays an important role in the operational safety of high-speed trains. In the process of train braking at high

$\bowtie$ Junsheng Qu

\section{0@bjtu.edu.cn}

1 School of Mechanical, Electronic and Control Engineering, Beijing Jiaotong University, Beijing 100044, China initial speed, the heat generated by friction causes the brake disc to produce a sharp temperature gradient, which leads to high thermal stress ${ }^{[1]}$. Thermal fatigue is the main cause of brake disc failure, which directly affects the reliability of the brake disc and train operation safety ${ }^{[2,3]}$. At present, the finite element method is widely used to analyse the temperature fields and stress fields in the braking process, and the main method is the thermo-mechanical coupling method ${ }^{[4]}$. In the actual braking process, the temperature field distribution of the brake disc directly affects the distribution of the thermal stress field. The deformation of the brake disc also has a certain impact on the distribution of the temperature field [5].

To optimize the structure of the brake disc and improve its service performance, scholars have carried out extensive research by simulation and experiment. Jean-Gabriel et al. established an analytical model for the multi-point temperature calculation on the disk surface of high-speed trains, which can accurately calculate the three-dimensional temperature inside the disk in a short time ${ }^{[6]}$. Adam et al. studied the effect of cooling on the temperature distribution of the brake disc during cyclic braking by simulation and the results show that convective heat transfer cannot reduce the maximum temperature of the brake disc in a single braking process ${ }^{[7]}$. Hwang and $\mathrm{Wu}$ analysed the thermo-mechanical coupling behaviour of a single brake of a ventilated brake disc by using a three-dimensional finite element model and concluded that the uneven distribution of the contact pressure led to an uneven temperature field and the temperature field affected the change in the contact pressure ${ }^{[8]}$. Benhassine et al. compared and analysed the temperature field, stress 
field and contact pressure of three kinds of axle-mounted brake disc materials and summarized the influence of the temperature field on the contact pressure and stress field ${ }^{[9]}$. Suxia Zhou et al. studied the fracture of brake disc bolts under a section downhill of the Lanzhou-Wulumuqi railway line. The finite element model of bolt thread with hexahedral meshes was established to obtain the stress states, temperature and the change of bolt performance during continuous braking ${ }^{[10]}$. Wang et al. analysed the load evolution of axle-mounted brake disc bolts in the process of long slope continuous braking and studied the influence of the preload, thermal expansion coefficient and other factors on the load of brake disc connecting bolts ${ }^{[11]}$. Wang et al. studied the temperature trends of train brake discs in the process of high-speed braking and concluded that the change in temperature causes fluctuation in the instantaneous friction coefficient and a distribution of thermal stress on the brake disc, which implied thermal damage ${ }^{[12]}$. B. Ghadimi et al. conducted a three-dimensional simulation analysis on the brake temperature field of the wheel-mounted brake disc of an ER24PC locomotive and compared the results with experimental results. This research shows that the convection design of the brake disc has little effect on the maximum temperature during the braking process and the maximum temperature value depends on the braking deceleration ${ }^{[13]}$. Dae-Jin et al. studied the influence of thermal stress on the contact surface of the brake disc under different contact pressure distributions by using a three-dimensional finite element model. It was found that under the condition of variable pressure distribution, the area where the maximum thermal stress appears is similar to the fatigue crack area of the actual disc brake ${ }^{[14]}$.

The theoretical and experimental results show that crack initiation usually comes from the bolt hole near the middle of the brake disc, and the bolt hole on the disc surface is the dangerous part of brake disc fatigue ${ }^{[15]}$. Figure 1 shows the fatigue cracks on the bolt holes of a wheel-mounted brake disc in practice. To reveal the causes of thermal fatigue cracks in brake discs, a three-dimensional thermo-mechanical coupling model of wheel-mounted brake discs of high-speed trains with bolts with the contact relations of various components is established. The temperature field, stress field, displacement field and bolt temperature of brake discs under $300 \mathrm{~km} / \mathrm{h}$ emergency braking conditions are simulated and analysed by the direct coupling method, and a full-scale bench test is carried out. The research results provide theoretical support for brake disc design, bolt selection and application of fault analysis.

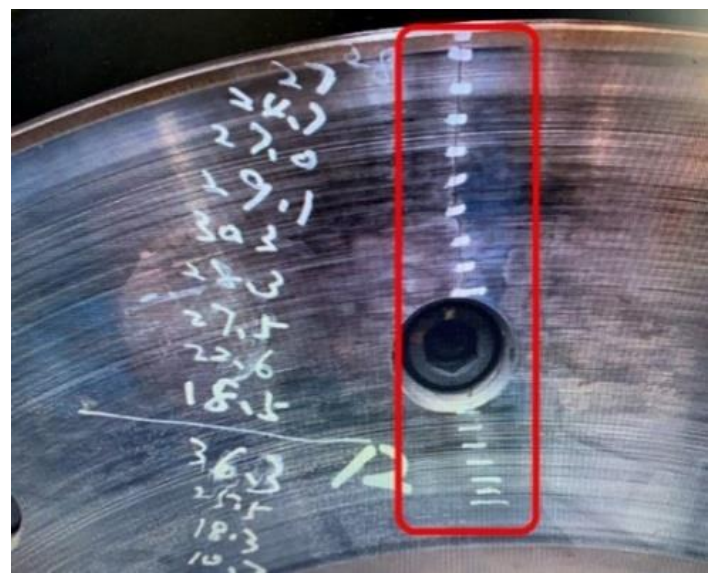

Figure 1 Fatigue crack at the bolt hole edge of the wheel-mounted brake disc.

\section{Finite element simulation of wheel-mounted brake disc}

\subsection{Finite element model and material properties}

The calculation model includes a wheel-mounted brake disc, wheel and connecting bolt, as shown in Figure 2. Based on the symmetry of the structure and the distribution of the heat dissipation ribs, this paper uses a one-sixth geometric model and selects SOLID5 elements of multiple physical fields to establish the finite element model (33198 elements and 44330 nodes in total). Additionally, contact elements are established between the bolt and brake disc, brake disc and wheel spoke, and bolt and sleeve to simulate real heat conduction. The fully-constrained is imposed to the wheel hub, the symmetry constraint is imposed to the symmetrical surface, and the heating load is imposed to the friction surface of the brake disc. The finite element model is shown in Figure 3.

In addition to the mechanical parameters, the boundary conditions need to consider the convective heat transfer coefficient, heat radiation and heat flux. The brake disc body is made of cast steel, and the connecting bolt is made of high-strength alloy steel. The material parameters and 
thermo-physical properties are listed in Table 1 and Table 2 , respectively, and the materials are isotropic.

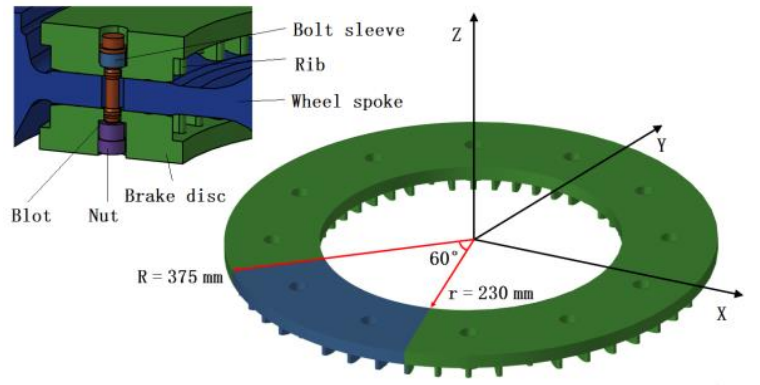

Figure 2 Geometric model of axle-mounted brake disc

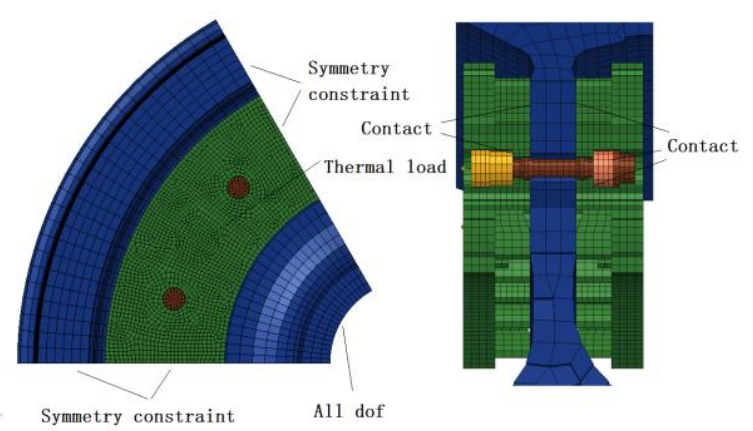

Figure 3 Finite element model

\subsection{Calculation of thermal load and relevant} parameters

In the process of emergency braking, the brake disc converts the kinetic energy of the train into heat energy through friction. The heat flux is imposed on the friction surface of the brake disc to simulate the friction heat input load between the brake disc and the brake pad.

Based on the theoretical basis of the brake friction and thermal analysis, the following assumptions are made before calculating the heat flux: 1) The brake process is a uniform deceleration process, and the brake pad pressure is constant during the braking process. 2) The friction coefficient between the brake disc and the pad is constant during the braking process. 3) The friction heat formed in the process of braking is generated on the contact surface, and it is uniformly input to the friction surface of the brake disc via heat flux. The heat flux is calculated by the energy conversion method, and the formula is as follows ${ }^{[16]}$ :

$$
q(t)=\frac{-\eta M a v_{(t)}}{2 n A}
$$

where: $\eta$ is the thermal absorption rate of the brake disc, $\mathrm{M}$ is the mass of the whole vehicle, $n$ is the number of the brake discs of the whole vehicle, $A$ is the friction surface area of the brake disc, $a$ is the braking deceleration, $v_{(t)}$ is the vehicle speed.

The contact thermal conductivity is the reciprocal of the contact thermal resistance, which is related to the surface roughness, contact pressure, contact temperature and other parameters of the contact surface ${ }^{[17]}$. The higher the contact pressure and the greater the temperature difference between the two contact surfaces are, the higher the contact thermal conductivity is, and the contact thermal conductivity decreases with increasing contact surface roughness ${ }^{[18]}$. The contact thermal conductivity is also related to the materials of the two contacting objects. The calculation formula of the contact thermal conductivity of the same material is as follows ${ }^{[19]}$ :

$$
\begin{gathered}
h_{c}=10^{5}\left[c_{1} \lambda \frac{\left(\frac{p}{H_{V}}\right)^{2 / 3}}{R a_{t}^{m}}+\frac{c_{2}}{R a_{t}^{n}}\right] \\
R a_{t}=R a_{1}+R a_{2} \\
c_{1}=0.06 \in[0.055,0.065] \\
c_{2}=0.09 \in[0.085,0.095] \\
\mathrm{m}=0.8 \in[0.8,0.9] \\
\mathrm{n}=0.7 \in[0.7,0.8]
\end{gathered}
$$

where: $p(\mathrm{MPa})$ is the contact pressure, $\lambda(\mathrm{W} / \mathrm{mK})$ is the thermal conductivity of the material, $H v$ is the Vickers hardness of the material. $R a_{1}$ and $R a_{2}$ are the surface roughness of the two contact surfaces. $c_{1}, c_{2}, \mathrm{~m}$ and $\mathrm{n}$ are scattered over the range shown in the equation. 
Table. 1 Brake disc material properties

\begin{tabular}{|c|c|c|c|c|c|c|c|}
\hline $\begin{array}{c}\text { Temperatur } \\
\mathrm{e}\left({ }^{\circ} \mathrm{C}\right)\end{array}$ & $\begin{array}{c}\text { Tensile Strength } \\
\text { (MPa) }\end{array}$ & $\begin{array}{l}\text { Yield Strength } \\
\text { (MPa) }\end{array}$ & $\begin{array}{l}\text { Thermal Expansion } \\
\text { Coefficient }\left(10^{-6}\right)\end{array}$ & $\begin{array}{l}\text { Elastic Modulus } \\
\qquad(\mathrm{GPa})\end{array}$ & $\begin{array}{l}\text { Poisson's } \\
\text { Ratio }\end{array}$ & $\begin{array}{l}\text { Thermal } \\
\text { Conductivity } \\
\left(\mathrm{W} \cdot \mathrm{m}^{-1} \cdot \mathrm{K}^{-1}\right)\end{array}$ & $\begin{array}{c}\text { Specific Heat } \\
\text { Capacity } \\
\left(\mathrm{J} \cdot \mathrm{kg}^{-1} \cdot \mathrm{K}^{-1}\right)\end{array}$ \\
\hline 20 & 1235 & 1137 & 11.6 & 211 & 0.28 & 45.2 & 473 \\
\hline 200 & 1130 & 1030 & 11.6 & 202 & 0.28 & 43.6 & 523 \\
\hline 400 & 1050 & 945 & 13.6 & 187 & 0.29 & 43.9 & 607 \\
\hline 600 & 565 & 420 & 14.2 & 168 & 0.3 & 42.3 & 754 \\
\hline 700 & 191 & 100 & 14.2 & 152 & 0.31 & 43.8 & 805 \\
\hline \multicolumn{8}{|c|}{ Table. 2 Bolt material properties } \\
\hline $\begin{array}{c}\text { Temperatur } \\
\mathrm{e}\left({ }^{\circ} \mathrm{C}\right)\end{array}$ & $\begin{array}{c}\text { Tensile Strength } \\
\text { (MPa) }\end{array}$ & $\begin{array}{l}\text { Yield Strength } \\
\text { (MPa) }\end{array}$ & $\begin{array}{l}\text { Thermal Expansion } \\
\text { Coefficient }\left(10^{-6}\right)\end{array}$ & $\begin{array}{l}\text { Elastic Modulus } \\
\qquad(\mathrm{GPa})\end{array}$ & $\begin{array}{c}\text { Poisson's } \\
\text { Ratio }\end{array}$ & $\begin{array}{c}\text { Thermal } \\
\text { Conductivity } \\
\left(\mathrm{W} \cdot \mathrm{m}^{-1} \cdot \mathrm{K}^{-1}\right)\end{array}$ & $\begin{array}{c}\text { Specific Heat } \\
\text { Capacity } \\
\left(\mathrm{J} \cdot \mathrm{kg}^{-1} \cdot \mathrm{K}^{-1}\right)\end{array}$ \\
\hline 20 & 1160 & 755 & 16.8 & 199 & 0.3 & 38.3 & 524 \\
\hline 200 & 968 & 714 & 16.8 & 199 & 0.3 & 36.4 & 575 \\
\hline 400 & 919 & 651 & 17.4 & 199 & 0.3 & 32.7 & 607 \\
\hline 600 & 880 & 620 & 17.8 & 157 & 0.3 & 29.1 & 752 \\
\hline
\end{tabular}

In the process of train braking, the brake disc conducts forced convection heat exchange with the air. When the train is stationary, the brake disc and air conduct natural convection heat exchange, which transfers heat from the brake disc to the air. Convective heat transfer is related to the fluid flow state, fluid physical properties, temperature and geometry. There is also radiant heat exchange between brake disc components. According to the theory of heat transfer, the convective heat transfer coefficient ${ }^{[20]}$ and the heat radiation coefficient ${ }^{[15]}$ are obtained:

$$
\begin{gathered}
h_{t}=0.664\left(\frac{L \mu}{\gamma}\right)^{1 / 2} \operatorname{Pr}^{1 / 3} \frac{\lambda_{a}}{L} \\
h_{\mathrm{r}}=\varepsilon \sigma\left(T^{2}+T_{\mathrm{a}}^{2}\right)\left(T+T_{\mathrm{a}}\right)
\end{gathered}
$$

where: $\operatorname{Pr}$ is Prandtl number, $\lambda_{a}$ is air thermal conductivity coefficient (W/mK), $L$ is wall length (m), $\mu$ is air flow velocity $(\mathrm{m} / \mathrm{s}), \gamma$ is air kinematic viscosity $\left(\mathrm{m}^{2} / \mathrm{s}\right), \varepsilon$ is emission coefficient, $\sigma$ is Boltzmann constant, $T_{a}$ is far-field temperature.

In the process of braking, the convective heat transfer coefficient of the brake disc surface at different positions and at different times is different. In other words, the convective heat transfer coefficient varies with space and time ${ }^{[21]}$.

\subsection{Thermo-elastic stress field}

The transient temperature field is taken as the load condition into the following formula to obtain the thermal stress field of the brake disc. If the strain tensor $\varepsilon$ and Cauchy stress tensor $\sigma$ are proportional to the temperature variation ${ }^{[15]}$, then

$$
\begin{gathered}
\left\{\boldsymbol{\varepsilon}_{0}\right\}=\alpha\left(\mathbf{T}-\mathbf{I} T_{0}\right)=\alpha \Delta \mathbf{T} \\
\{\boldsymbol{\varepsilon}\}=\nabla_{\mathrm{s}} \mathbf{u} \\
\{\boldsymbol{\sigma}\}=\mathbf{D} \alpha \Delta \mathbf{T}
\end{gathered}
$$

where I and D are the unit vector and the elastic matrix respectively, and $\alpha$ is the thermal expansion coefficient of the material of brake disc. Then the governing equations and the corresponding boundary conditions of the thermo-elastic problem in the single problem domain $\Omega$ are obtained,

$$
\begin{gathered}
\nabla \cdot \boldsymbol{\sigma}+\mathbf{b}=0 \\
\mathbf{u}=\mathbf{u}_{0}
\end{gathered}
$$

where $\mathbf{b}$ and $\mathbf{u}_{0}$ are volume force $(=0)$ and symmetrical boundary displacement condition $(=0)$. 


\section{A full scale bench test}

An emergency brake test was carried out on a full-scale brake dynamic test bed (ID281975) at high speed. Thermocouples were arranged $3 \mathrm{~mm}$ below the middle of the friction ring of the brake disc, every $120^{\circ}$ and at the bolt root, as shown in Figure 4. The temperature of the brake disc friction ring and bolt was recorded in real time.

According to the pressure curve of the emergency braking of a high-speed train, the pressure in emergency braking should be applied in stages during the test. If the initial braking speed is $250 \mathrm{~km} / \mathrm{h}$ and below, the braking pressure is $17.5 \mathrm{kN}$; otherwise, the braking pressure is $10.5 \mathrm{kN}$. The relationship between brake pressure and speed is shown in Figure 5.

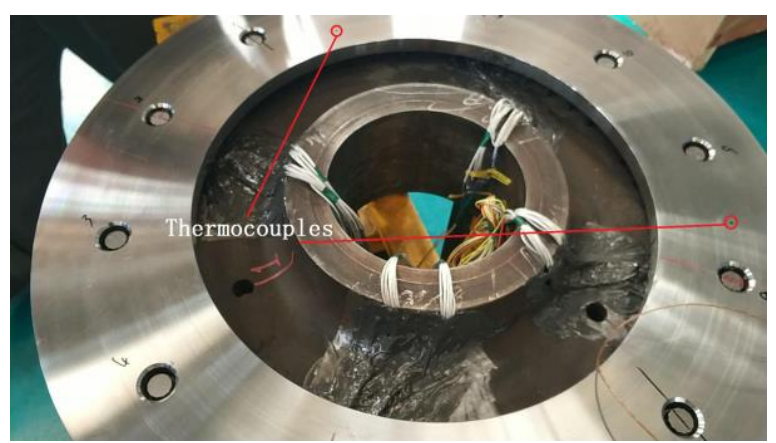

Figure 4 Distribution diagram of the thermocouple of the brake disc friction ring.

Before the test, 20 emergency braking events with an initial speed of $120 \mathrm{~km} / \mathrm{h}$ were carried out to reduce the influence of uneven contact on the temperature field distribution of the brake discs. The temperature increases of the brake disc and connecting bolt under emergency braking conditions with initial speeds of $160-350 \mathrm{~km} / \mathrm{h}$ were measured in the test, as shown in Table. 3.

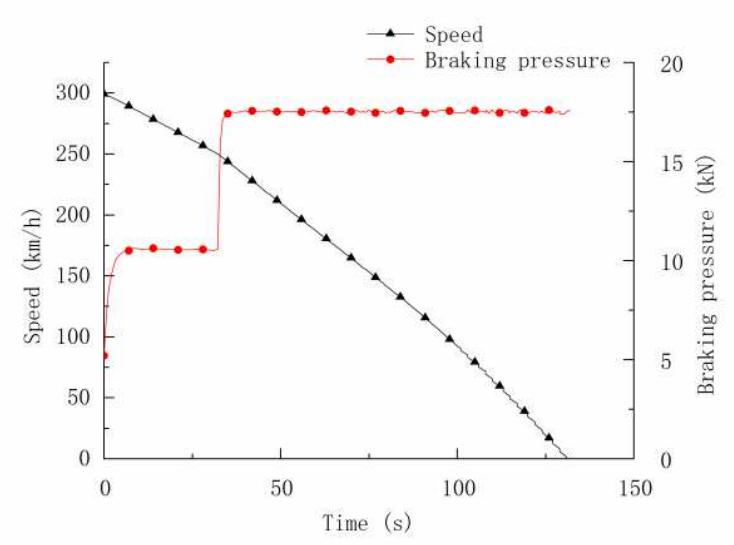

Figure 5 Change of braking pressure with speed at initial speed of $300 \mathrm{~km} / \mathrm{h}$

Table. 3 Maximum temperature rise of brake disc friction ring and bolt in emergency braking with different initial speeds

\begin{tabular}{|c|c|c|c|c|c|c|c|}
\hline $\begin{array}{l}\text { Initial Velocity } \\
\qquad / \mathrm{km} / \mathrm{h}\end{array}$ & 160 & 200 & 250 & 280 & 300 & 330 & 350 \\
\hline Braking Time/s & 43 & 59 & 83 & 104 & 130 & 151 & 146 \\
\hline \multicolumn{8}{|l|}{ Maximum } \\
\hline \multicolumn{8}{|l|}{ Temperature } \\
\hline Rise of Friction & 217.2 & 303.6 & 357.0 & 404.4 & 397.5 & 455.4 & 554.3 \\
\hline \multicolumn{8}{|l|}{ Ring Surface } \\
\hline \multicolumn{8}{|l|}{$/{ }^{\circ} \mathrm{C}$} \\
\hline \multicolumn{8}{|l|}{ Maximum } \\
\hline Temperature & 57.4 & 90.8 & 155.6 & 184.5 & 199.0 & 227.8 & 263.4 \\
\hline Rise of Bolt $/{ }^{\circ} \mathrm{C}$ & & & & & & & \\
\hline
\end{tabular}

\section{Calculation results}

The temperature field, displacement field, stress field and bolt temperature of the wheel-mounted brake disc under $300 \mathrm{~km} / \mathrm{h}$ emergency braking conditions are simulated and analysed by using the established three-dimensional thermo-mechanical coupling model of the wheel-mounted brake disc with bolts and considering the contact relationship of each component.

\subsection{Temperature field distribution}

The comparison between the calculated value and the test value of the surface temperature of the friction ring during emergency braking with an initial speed of $300 \mathrm{~km} / \mathrm{h}$ is shown in Figure 6 (a), in which the 
braking time is $130 \mathrm{~s}$. At the beginning of braking, the surface temperature of the friction ring increases rapidly and reaches the maximum temperature before the end of braking. The highest temperature does not occur at the end of braking, and the temperature decrease starts from the balance between the heat input and dissipation. After the brake, the natural convection heat transfer begins, and the rate of the decrease in temperature tends to be gentle with increasing time. In the first $32 \mathrm{~s}$, the rate of increase of the surface temperature of the friction ring increases because the speed decreases to $250 \mathrm{~km} / \mathrm{h}$, the braking pressure increases from $10.5 \mathrm{kN}$ to $17.5 \mathrm{kN}$, and the heat flux input increases. The calculated value of the highest temperature of the surface of the friction ring is $414^{\circ} \mathrm{C}(102 \mathrm{~s}$ after the start of braking), and the test value is $423^{\circ} \mathrm{C}(109 \mathrm{~s}$ after the start of braking), with an error of $2 \%$.

The comparison between the calculated value and the test value with time is shown in Figure 6 (b). The increase in the temperature of the bolt is mainly caused by the conduction of heat on the surface of the friction ring through the brake disc body, so the rate of the increase in temperature is lower than that of the surface of the friction ring of the brake disc and the highest temperature occurs after the end of braking, later than that of the surface of the friction ring. The calculated value of the maximum temperature of the bolt is $197^{\circ} \mathrm{C}$ (185 s after the start of braking), and the test value is $225^{\circ} \mathrm{C}$ ( $154 \mathrm{~s}$ after the start of braking), with an error of $12 \%$. The error mainly comes from the material parameters, contact state, thermocouple installation and other factors.

Figure $7(a, b)$ shows the change in temperature with radius at different depth positions of the radiator rib and locating pin of the friction ring at the highest temperature of the brake disc, where $\mathrm{z}=0$ represents the surface of the friction ring. The temperature of the outer diameter is higher than that of the inner diameter, and the temperature of the middle part is lower than those of the inner and outer sides due to the effect of the radiator rib. Compared with the position of the radiator rib, the temperature difference between the centre of the surface of the friction ring and the inside and outside diameter of the locating pin is larger, which is related to the larger volume and higher thermal capacity of the locating pin.

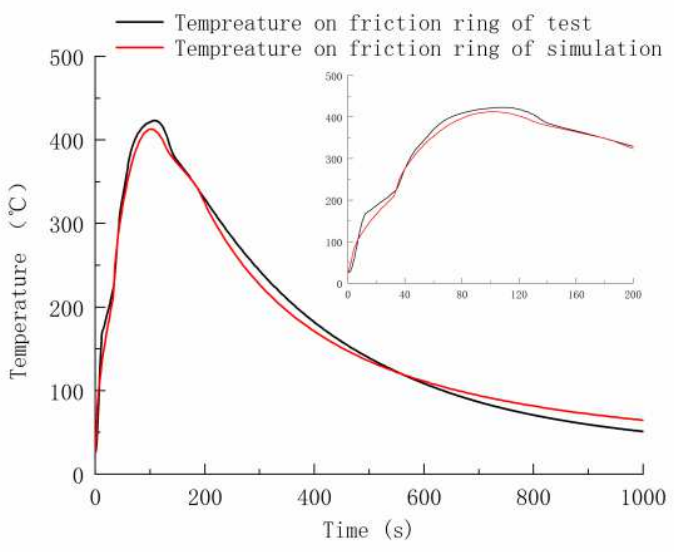

(a) The surface of the friction ring

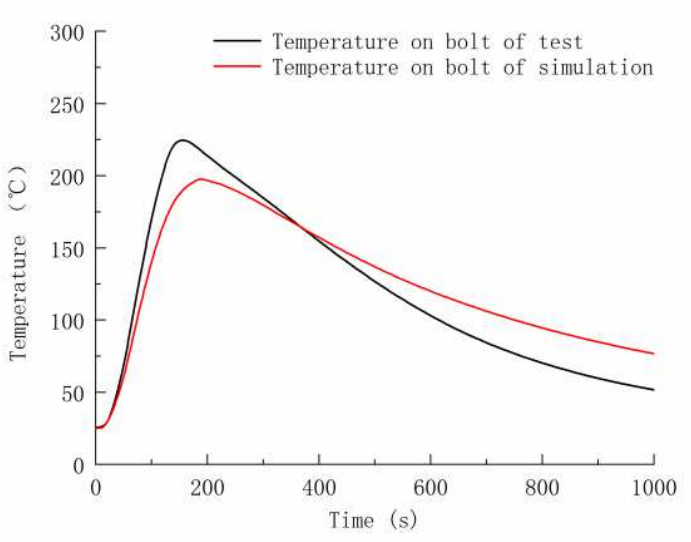

(b) Bolt root

Figure 6 Temperature simulation and test results comparison of the surface of the friction ring and bolt end under $300 \mathrm{~km} / \mathrm{h}$ emergency braking condition

The temperature contour of the brake disc at the time of brake pressure change (32 s), the time of the highest temperature on the surface of the friction ring (102 s), the end time of braking (130 s) and the time of the highest temperature at the end of the bolt (185 s) are shown in Figure 8. It can be seen that at the beginning of braking, the temperature changes uniformly. With the progress of braking, due to the influence of the geometry structure, heat conduction and heat dissipation, a larger temperature gradient appears on the surface of the friction ring, and a higher 
temperature and temperature gradient still exist at $55 \mathrm{~s}$ after braking.

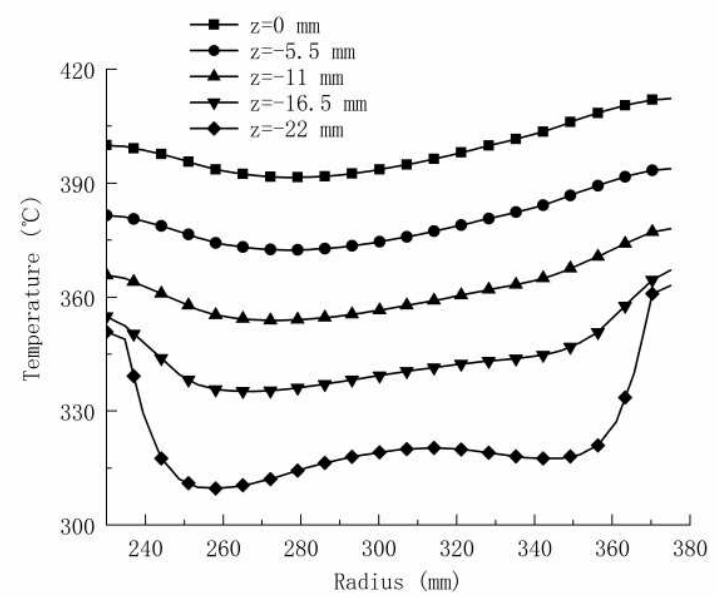

(a) Radiator rib

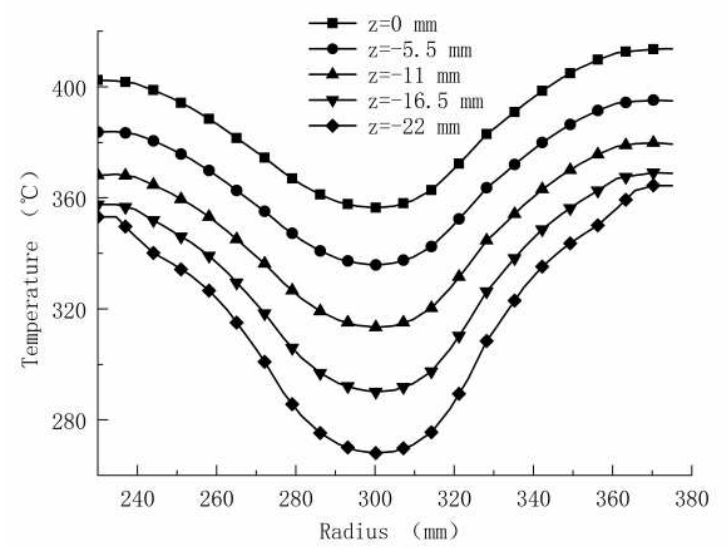

(b) Locating pin

Figure 7 Temperature changes with radius at different depths from the radiator rib and locating pin of the friction ring surface at the highest temperature of the brake disc
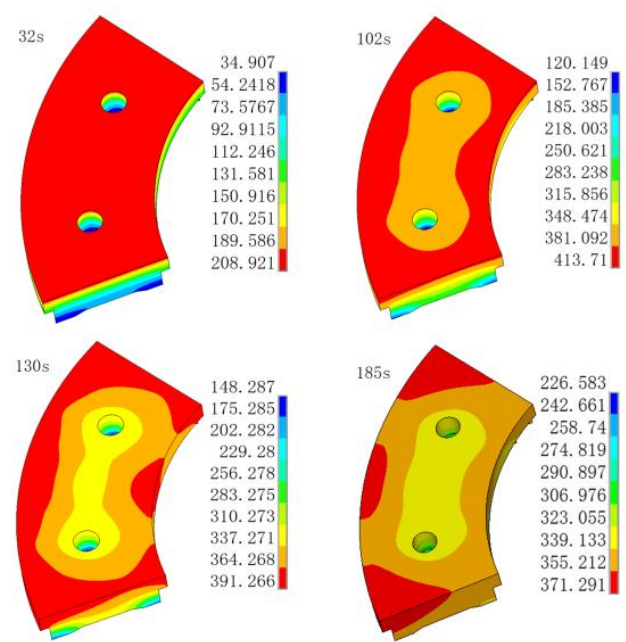

Figure 8 Temperature contour of brake disc

\subsection{Stress field distribution}

The radial stress and circumferential stress at the bolt hole of the brake disc friction ring are shown in Figure 9. Figure 10 shows the circumferential stress contour of the brake disc at different times. Due to the influence of the bolt connection and temperature gradient, the circumferential stress of the brake disc is concentrated on the bolt hole and its corresponding edge of the friction ring during the braking process. Therefore, the maximum circumferential compressive stress and tensile stress at the bolt hole are $658 \mathrm{MPa}$ and $134 \mathrm{MPa}$, respectively. In the process of braking, there is a high alternating thermal stress range, which causes thermal fatigue cracks on the bolt holes of wheel-mounted brake discs under the action of multiple emergency braking cycles.

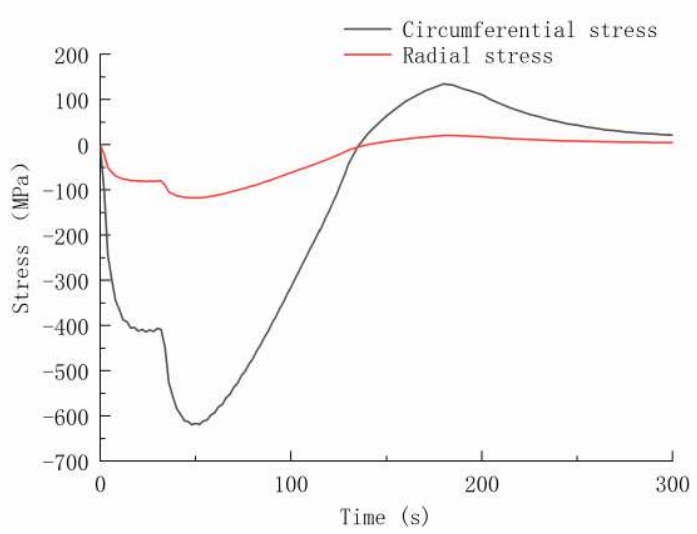

Figure 9 Circumferential stress and radial stress at bolt hole

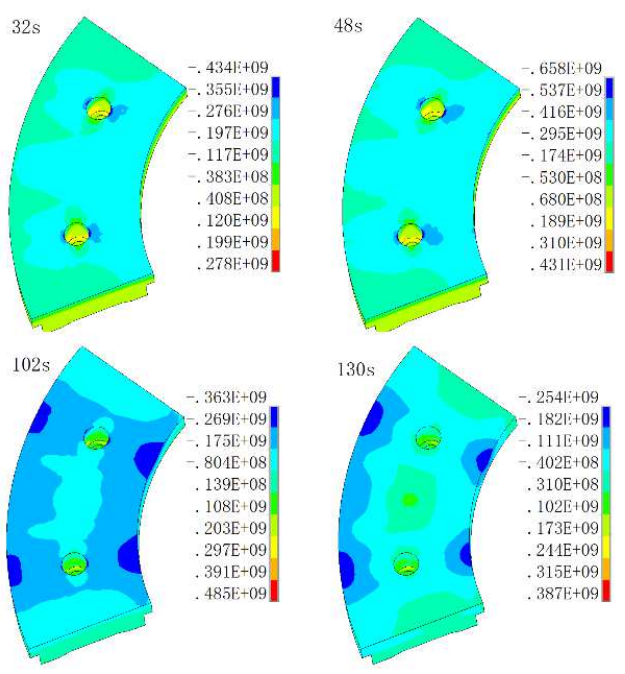

Figure 10 Circumferential stress contour of brake disc 


\subsection{The distribution of thermal deformation field}

The axial (normal) deformation contour of the brake disc at the moment of the maximum circumferential compressive stress ( $48 \mathrm{~s}$ ) on the friction ring surface is shown in Figure 11. Because of the bolt connection, the deformation of the bolt hole and locating pin affected by the temperature and mechanical constraints is less than that of the radiator rib, so it produces a higher compressive stress. In addition, Figure 12 indicates that the axial deformation of the middle part of the friction ring (radial $\mathrm{R}=318 \mathrm{~mm}$ ) is larger than that of the edge. Specifically, during the braking process, the central part of the whole disc body bulges outward, which not only increases the axial tensile load of the connecting bolt but also reduces the contact pressure between the radiator rib of the disc body and the wheel and reduces the contact friction. The stress state of the connecting bolts deteriorates continuously under the load of the wheel rail, so there is a risk of looseness and fracture.

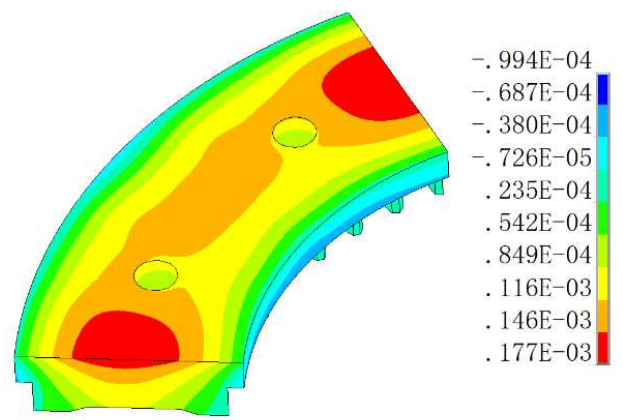

Figure 11 Axial deformation contour of brake disc

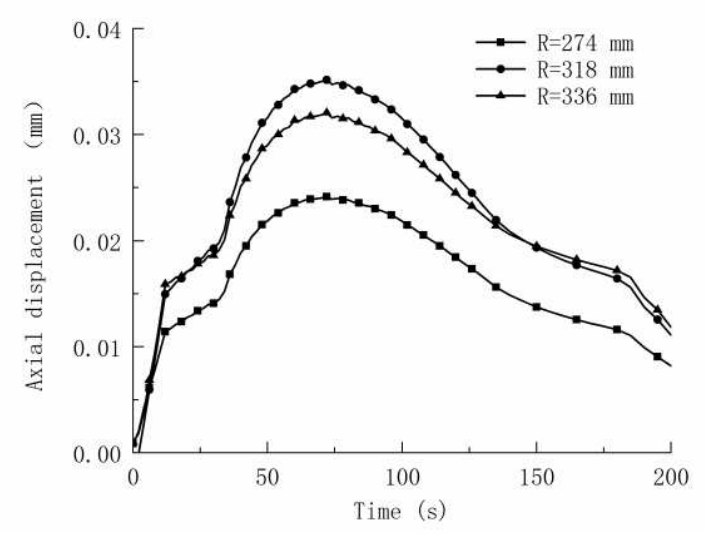

Figure 12 The axial displacement of the bolt hole on the contact surface of the disc body and the wheel changes with time

\section{Conclusion}

To reveal the cause of the fatigue cracking on the edge of the bolt hole on the surface of the brake disc of a high-speed train, a 3D thermo-mechanical coupling model of the wheel-mounted brake disc of the high-speed train is established in this paper, which includes the bolt and considers the contact relationship between the components. The temperature field and the stress field of the brake disc under the emergency braking condition of the initial speed of $300 \mathrm{~km} / \mathrm{h}$ are simulated and analysed and verified by a full-scale bench brake test. The main conclusions are as follows:

In the process of braking, there are two inflexions in the temperature increase curve due to the variable braking pressure. The calculated value of the highest temperature on the surface of the friction ring is $414^{\circ} \mathrm{C}$, the test value is $423^{\circ} \mathrm{C}$, and the error is $2 \%$. This verifies the accuracy of the calculation model and method.

The distribution of the temperature field of the brake disc is greatly affected by the geometry, and there are temperature gradients in the radial, circumferential and axial directions. In the process of braking, the main thermal stress is circumferential stress, the maximum alternating thermal stress is located at the edge of the bolt hole, the maximum circumferential compressive stress is $658 \mathrm{MPa}$ and the maximum circumferential tensile stress is $134 \mathrm{MPa}$. That is, multiple braking events can lead to the initiation and expansion of thermal fatigue cracks.

During the braking process, the axial deformation of the middle part of the friction ring is larger than that of the edge, and the thermal deformation of the disc body increases the axial tensile load of the connecting bolt and reduces the contact pressure between the radiator of the disc body and the wheel. The superposition effect of this working condition and wheel rail vertical impact load should be considered in bolt selection and design to prevent bolt loosening and fracture. 


\section{Declaration}

\section{Acknowledgements}

Not applicable

\section{Funding:}

Financial support was provided by the Beijing New-star Plan of Science and Technology project (Grant No.Z191100001119001) and the Research and Development Plan of China Railway Corporation project (Grant No.P2018J003).

\section{Availability of data and materials}

The datasets supporting the conclusions of this article are included within the article.

\section{Authors' Contributions:}

Conceptualization, methodology, formal analysis, investigation, Wenjing Wang and Junsheng Qu; writing-original draft preparation, Junsheng Qu and Ziyu Dong; software and data curation, Junsheng Qu. All authors have read and agreed to the published version of the manuscript.

\section{Conflicts of Interest:}

The authors declare no conflict of interest.

\section{Consent for publication}

Not applicable

Ethics approval and consent to participate Not applicable

\section{References}

[1] A Yevtushenko, M Kuciej, P Wasilewski. Experimental study on the temperature evolution in the railway brake disc. Theoretical \& Applied Mechanics Letters, 2019, 9, 308-311.

[2] S B Istoc, H Winner. Heat cracks in brake discs for heavy vehicles. Automotive and Engine Technology, 2018, 3, 61-68.

[3] F Bagnoli, F Dolce, M Bernabei. Thermal fatigue cracks of fire fighting vehicles gray iron brake discs. Engineering Failure
Analysis, 2009, 16, 152-163.

[4] M J Han, C H Lee, T W Park, et al. Low and high cycle fatigue of automotive brake discs using coupled thermo-mechanical finite element analysis under thermal loading. Journal of Mechanical Science and Technology, 2018, 32, 5777-5784.

[5] A Adamowicz, P Grzes. Analysis of disc brake temperature distribution during single braking under non-axisymmetric load. Applied Thermal Engineering, 2011, 31, 1003-1012.

[6] J G Bauzin, N Laraqi. Three-dimensional analytical calculation of the temperature in a brake disc of a high-speed train. Applied Thermal Engineering, 2019, 154, 668-675.

[7] A Adamowicz, P Grzes. Influence of convective cooling on a disc brake temperature distribution during repetitive braking. Applied Thermal Engineering, 2011, 31, 2177-2185.

[8] $\mathrm{P}$ Hwang, $\mathrm{X}$ Wu. Investigation of temperature and thermal stress in ventilated disc brake based on 3D thermo-mechanical coupling model. Journal of Mechanical Science and Technology, 2010, 24, 81-84.

[9] N Benhassine, A Haiahem, B B Said. A comparative study of the transient thermomechanical behavior of friction of the ceramic brake discs: Temperature field effect. Journal of Mechanical Science and Technology, 2019, 33, 233-240.

[10] S X Zhou, Z H Guo, X Y Bai. Fatigue fracture analysis of brake disc bolts under continuous braking condition. Engineering Failure Analysis, 2020, 115, 104588.

[11] X Wang, W J Wang, Y Wang. Variation of bolt loads of axle braking disc under continuous braking condition. Journal of Mechanical Engineering, 2018, 54, 71-77.

[12] Z Z Wang, J M Han, X L Liu, et al. Temperature evolution of the train brake disc during high-speed braking. Advances in Mechanical Engineering, 2019, II, 1-10. 
[13] B Ghadimi, F Kowsary, M Khorami. Thermal analysis of locomotive wheel-mounted brake disc. Applied Thermal Engineering, 2013, 51, 948-952.

[14] D J Kim, Y M Lee, J S Park, et al. Thermal stress analysis for a disk brake of railway vehicles with consideration of the pressure distribution on a frictional surface. Materials Science \& Engineering A, 2008, 483-484, 456-459.

[15] S C Wu, S Q Zhang, Z W Xu. Thermal crack growth-based fatigue life prediction due to braking for a high-speed railway brake disc. International Journal of Fatigue, 2016, 87, 359-369.

[16] S X Zhou, C L Sun, X H Zhao, et al. Simulation and analysis of $3 \mathrm{D}$ transient temperature field and stress field of cast steel brake disc of intercity trains. Journal of the China Railway Society, 2017, 39, 33-38.

[17] R F Dou, T R Ge, X L Liu, et al. Effects of contact pressure, interface temperature, and surface roughness on thermal contact conductance between stainless steel surfaces under atmosphere condition. International Journal of Heat and Mass Transfer, 2016, 94, 156-163.

[18] C L Yeh, C Y Wen, Y F Chen, et al. An experimental investigation of thermal contact conductance across bolted joints. Experimental Thermal and Fluid Science, 2001, 25, 349-357.

[19] T Fukuoka, M Nomura. Evaluation of thermal contact resistance at the interface of dissimilar materials. Journal of Pressure Vessel Technology, 2013, 135, 021403.

[20] Q Ding, J L Xie. The temperature field and stress tield calculation of brake disc based on 3-dimension model. Journal of the China Railway Society, 2002, 6, 34-38.

[21] Z J Luo, J Y Zuo. Conjugate heat transfer study on a ventilated disc of high-speed trains during braking. Journal of Mechanical Science and Technology, 2014, 28, 1887-1897.

\section{Biographical notes}

Junsheng Qu, born in 1995, is currently a $\mathrm{PhD}$ candidate at School of Mechanical, Electronic and Control Engineering, Beijing Jiaotong University, China. He received his bachelor degree from Beijing Jiaotong University, China, in 2017. His research interests include safe operation of carrier tools and the structural strength.

E-mail: 17116350@bjtu.edu.cn

Wenjing Wang, born in 1976, is currently a professor at School of Mechanical, Electronic and Control Engineering, Beijing Jiaotong University, China. She received her $\mathrm{PhD}$ degree from Beijing Jiaotong University, China, in 2004. Her research interests include safe operation of carrier tools, safety detection and control of carrier tools and the structural strength. E-mail: wjwang@bjtu.edu.cn

Ziyu Dong, born in 1997, is currently a PhD candidate at School of Mechanical, Electronic and Control Engineering, Beijing Jiaotong University, China. She received her bachelor degree from Beijing University of Civil Engineering and Architecture, China, in 2019. Her research interests include safe operation of carrier tools and the structural strength. E-mail: 19121396@bjtu.edu.cn 


\section{Figures}

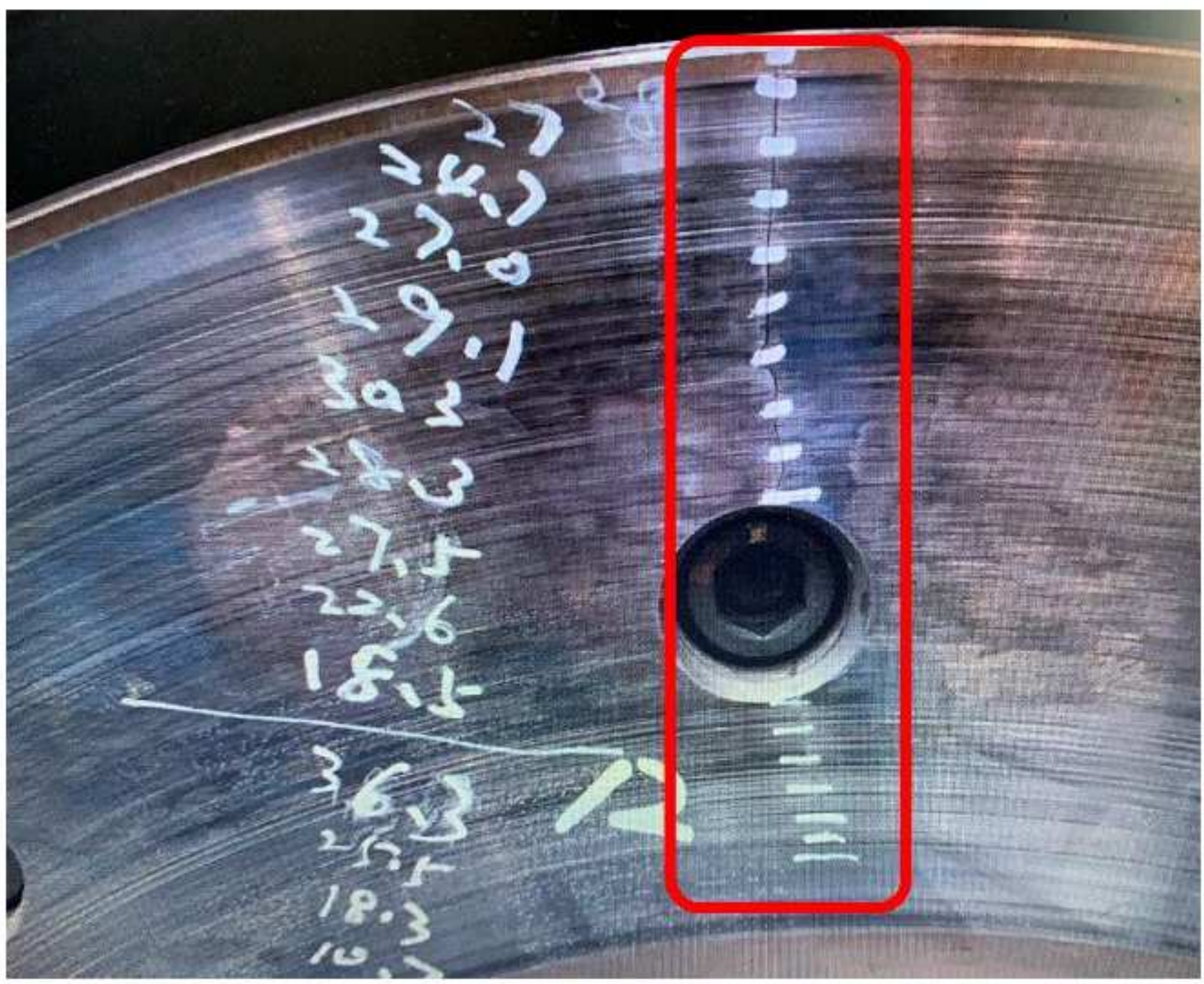

Figure 1

Fatigue crack at the bolt hole edge of the wheel-mounted brake disc. 


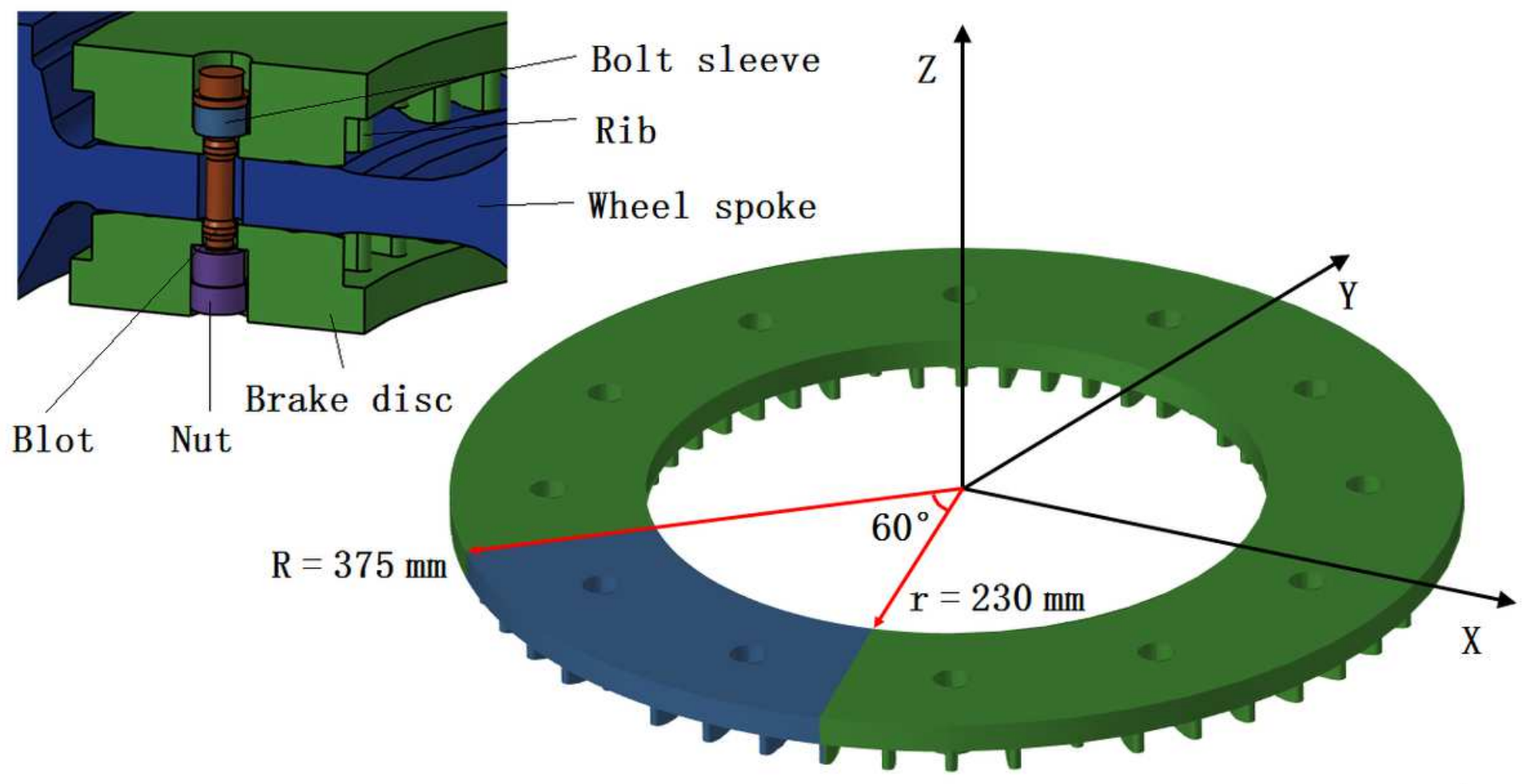

Figure 2

Geometric model of axle-mounted brake disc

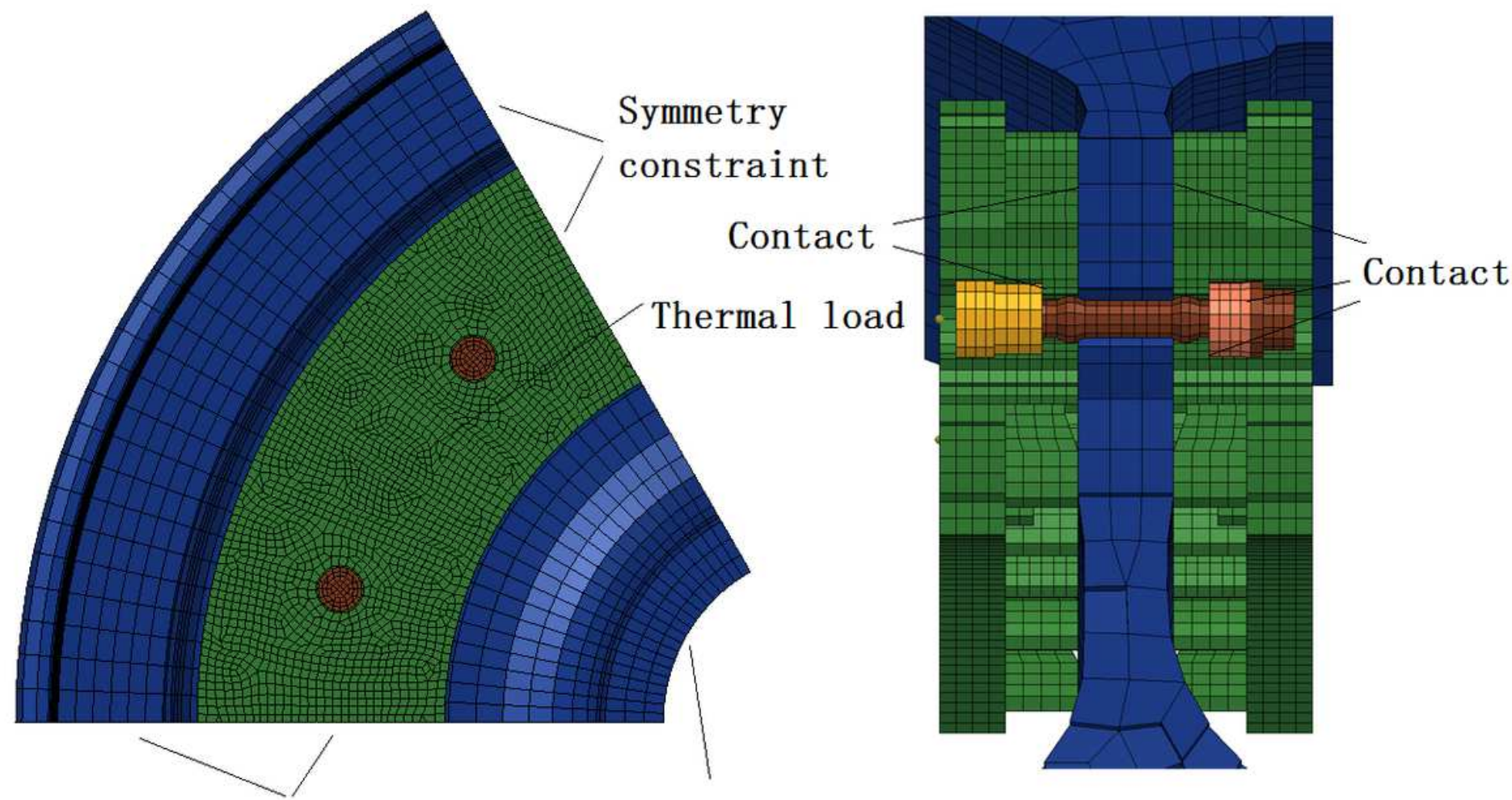

Symmetry constraint

A11 dof

Figure 3 
Finite element model

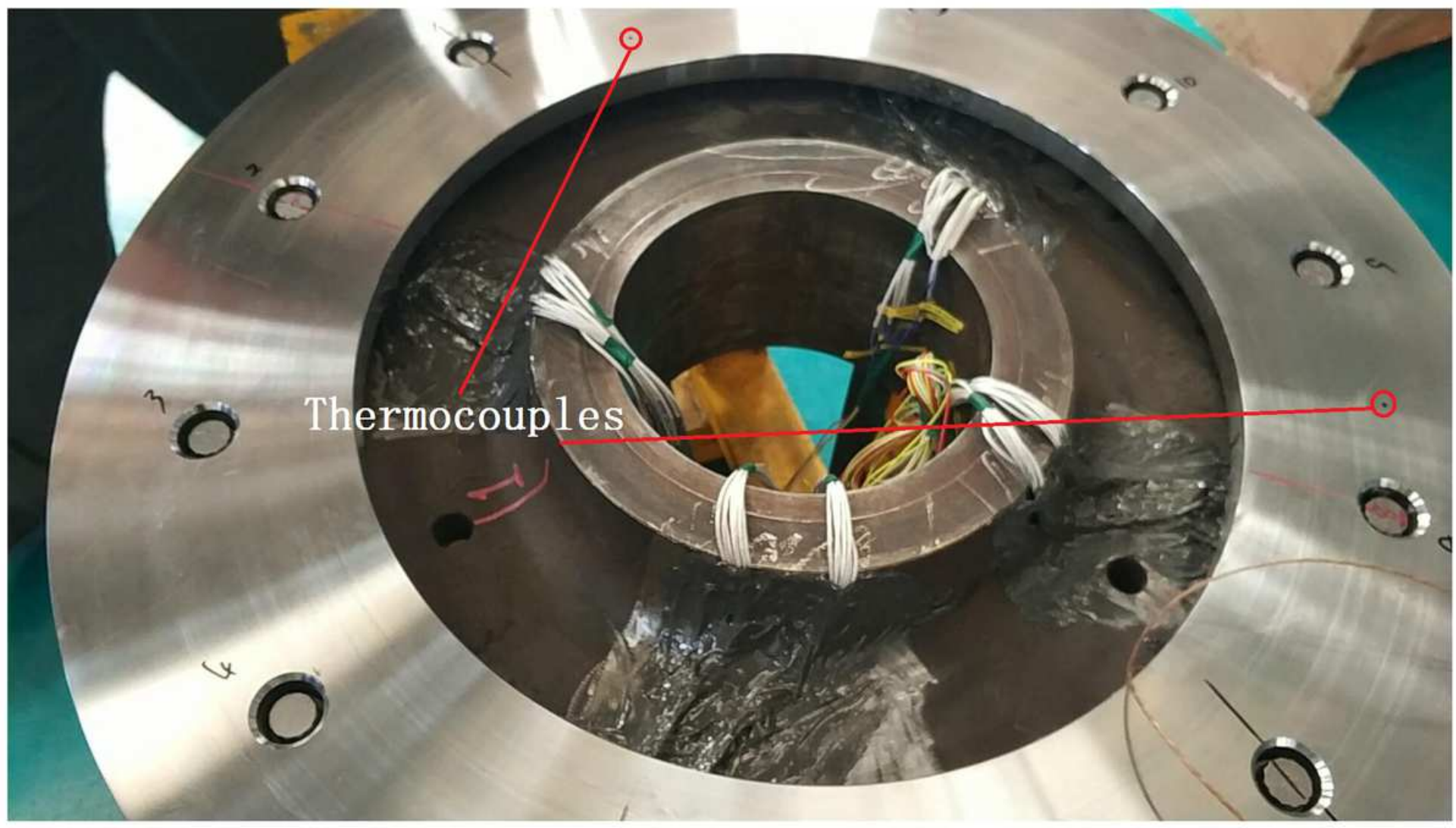

Figure 4

Distribution diagram of the thermocouple of the brake disc friction ring 


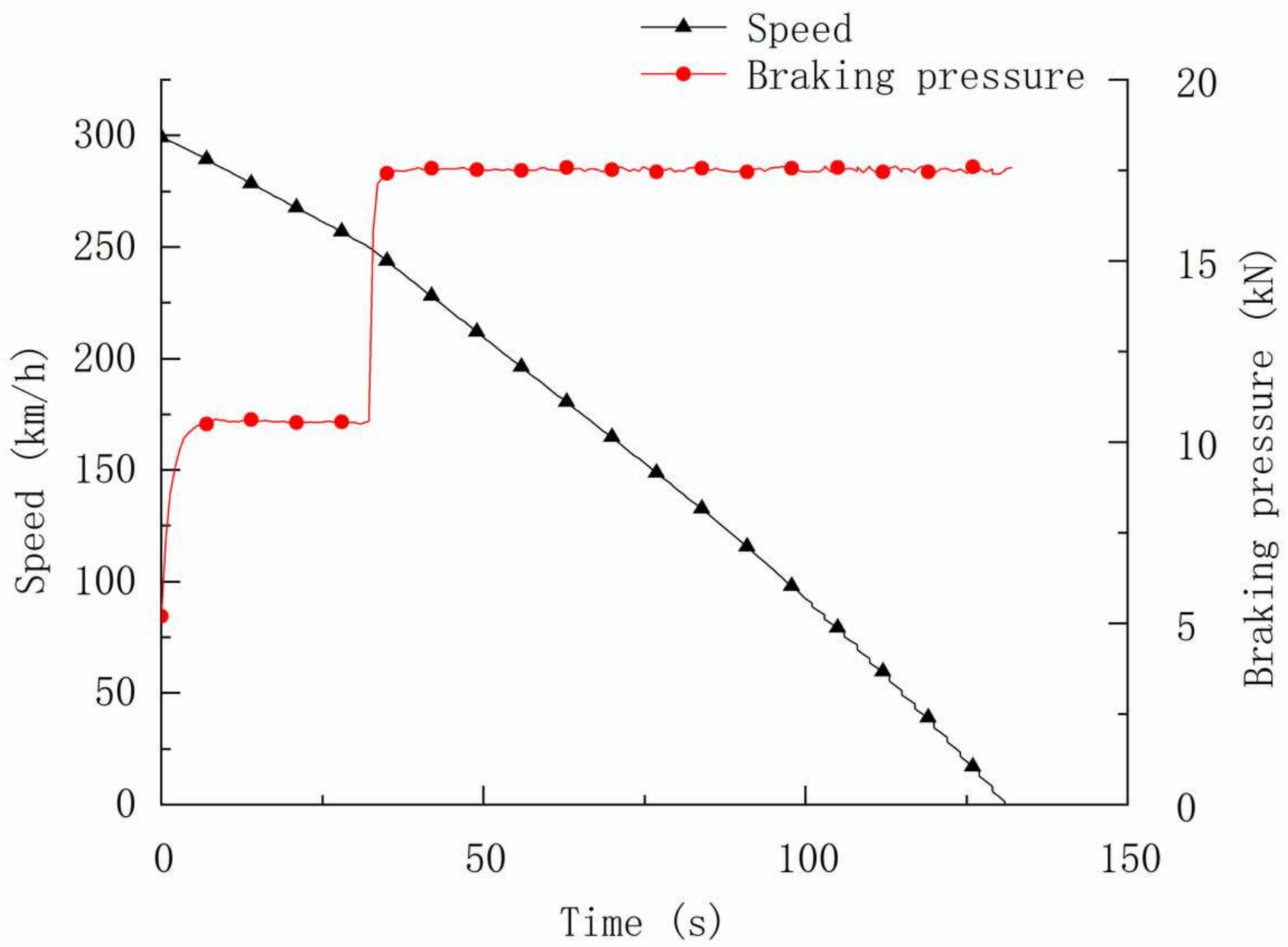

Figure 5

Change of braking pressure with speed at initial speed of $300 \mathrm{~km} / \mathrm{h}$
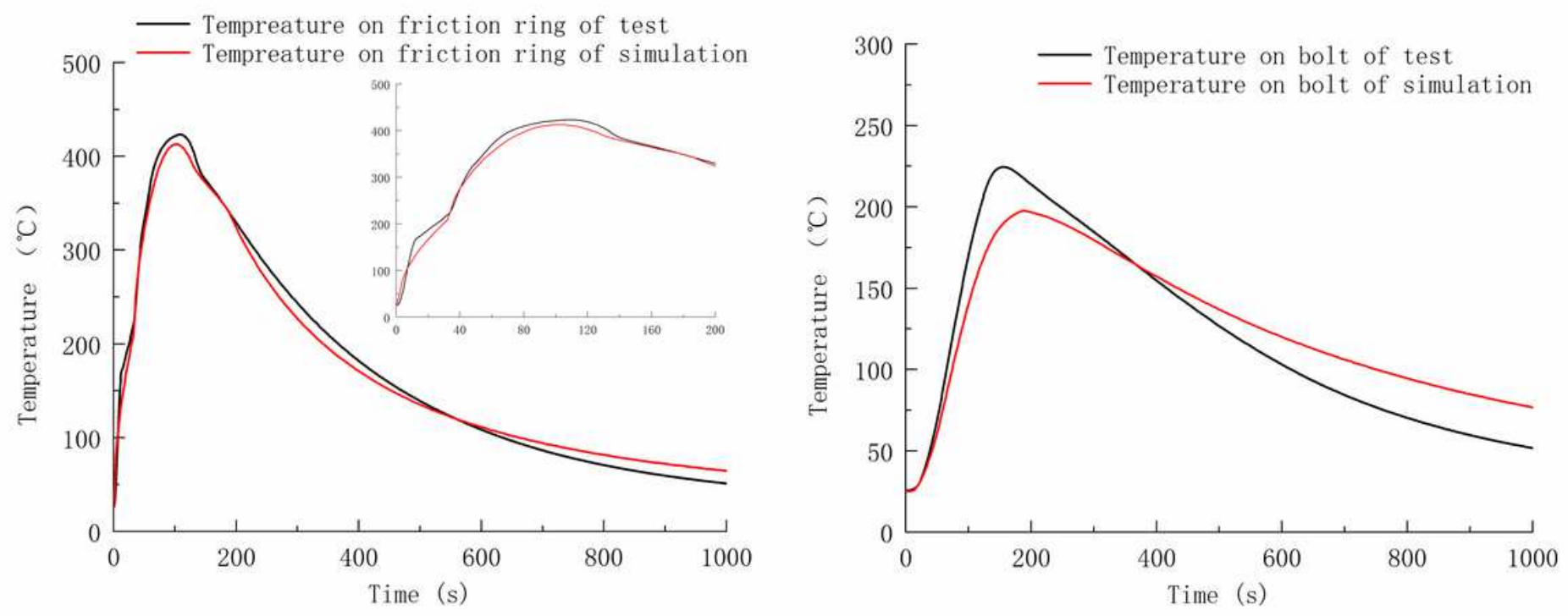
Figure 6

Temperature simulation and test results comparison of the surface of the friction ring and bolt end under $300 \mathrm{~km} / \mathrm{h}$ emergency braking condition
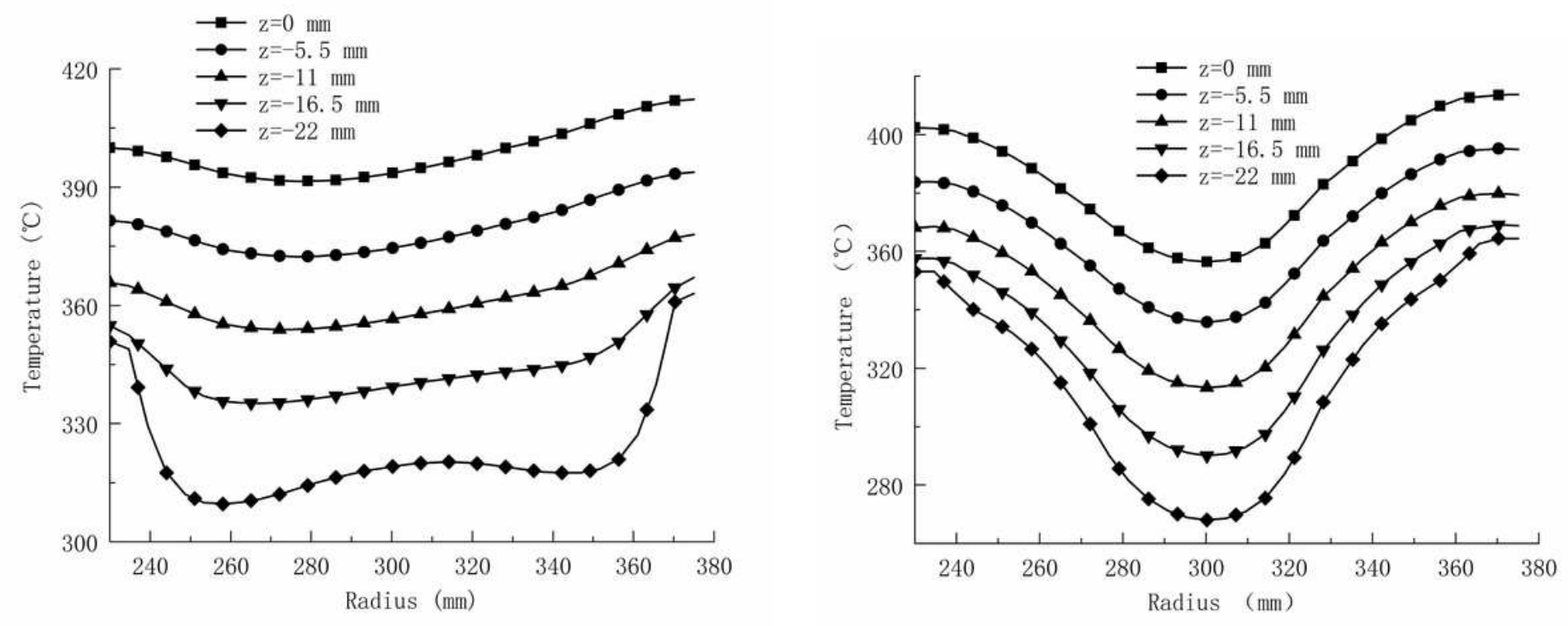

Figure 7

Temperature changes with radius at different depths from the radiator rib and locating pin of the friction ring surface at the highest temperature of the brake disc 

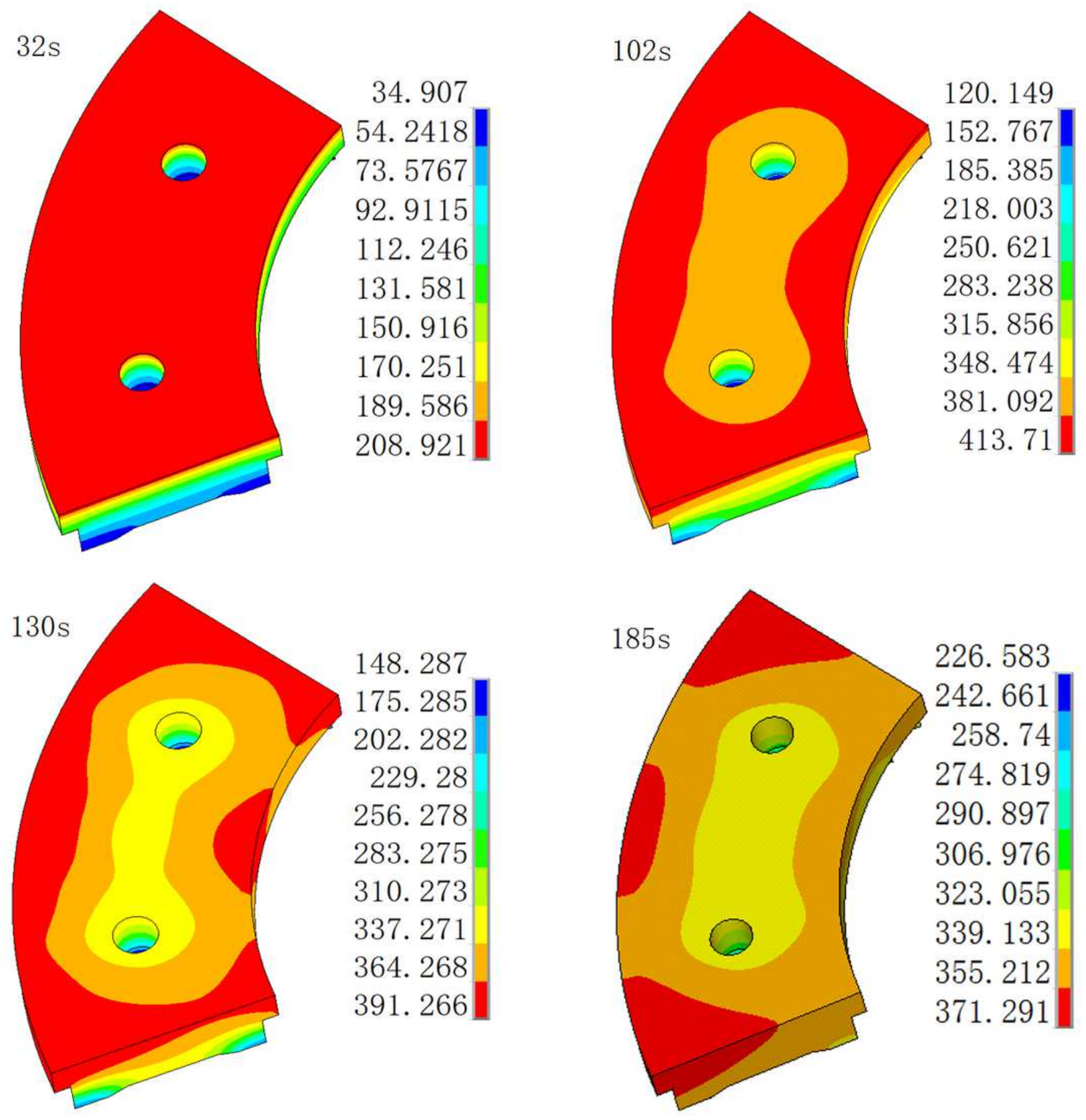

Figure 8

Temperature contour of brake disc 


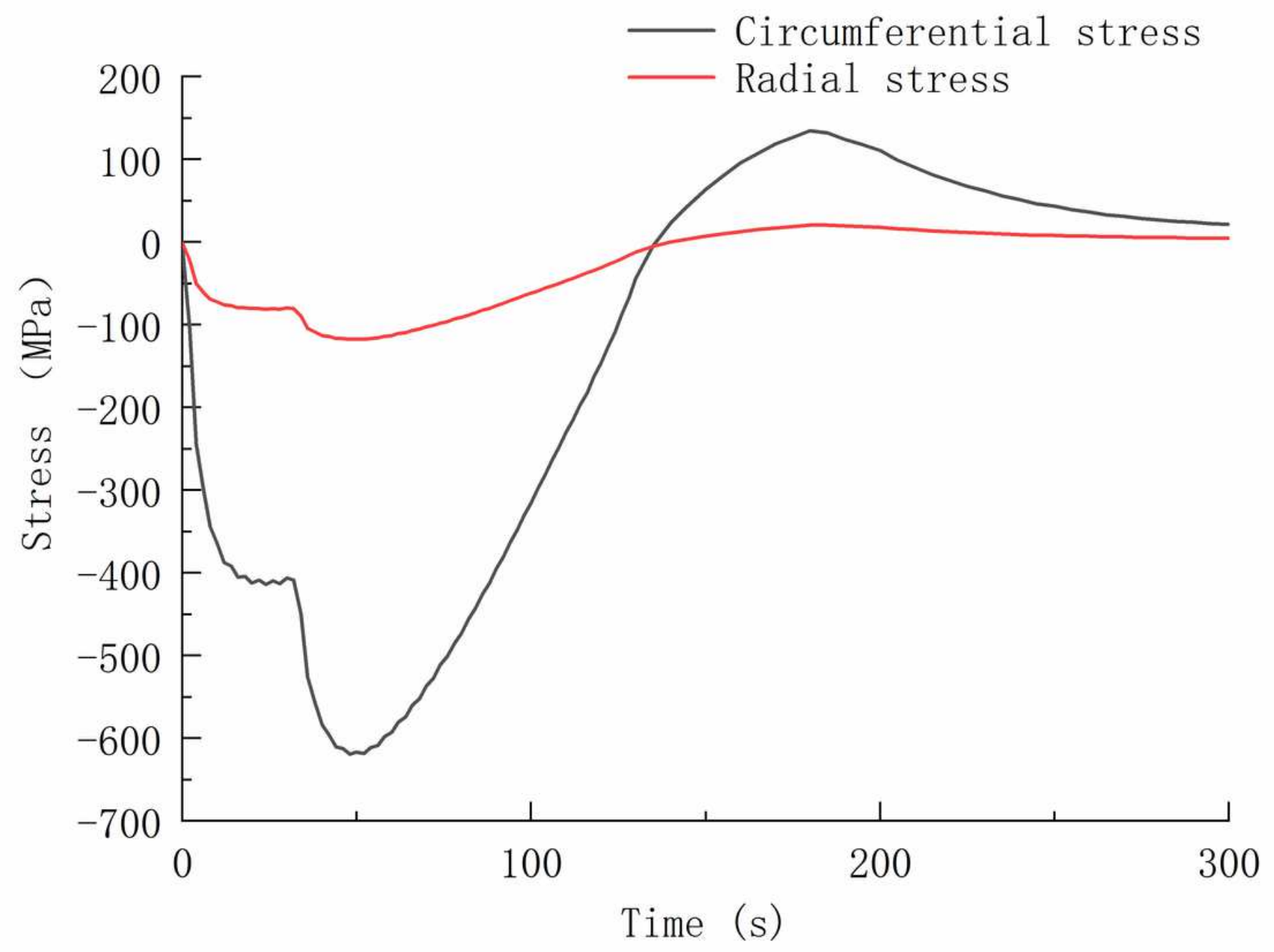

Figure 9

Circumferential stress and radial stress at bolt hole 

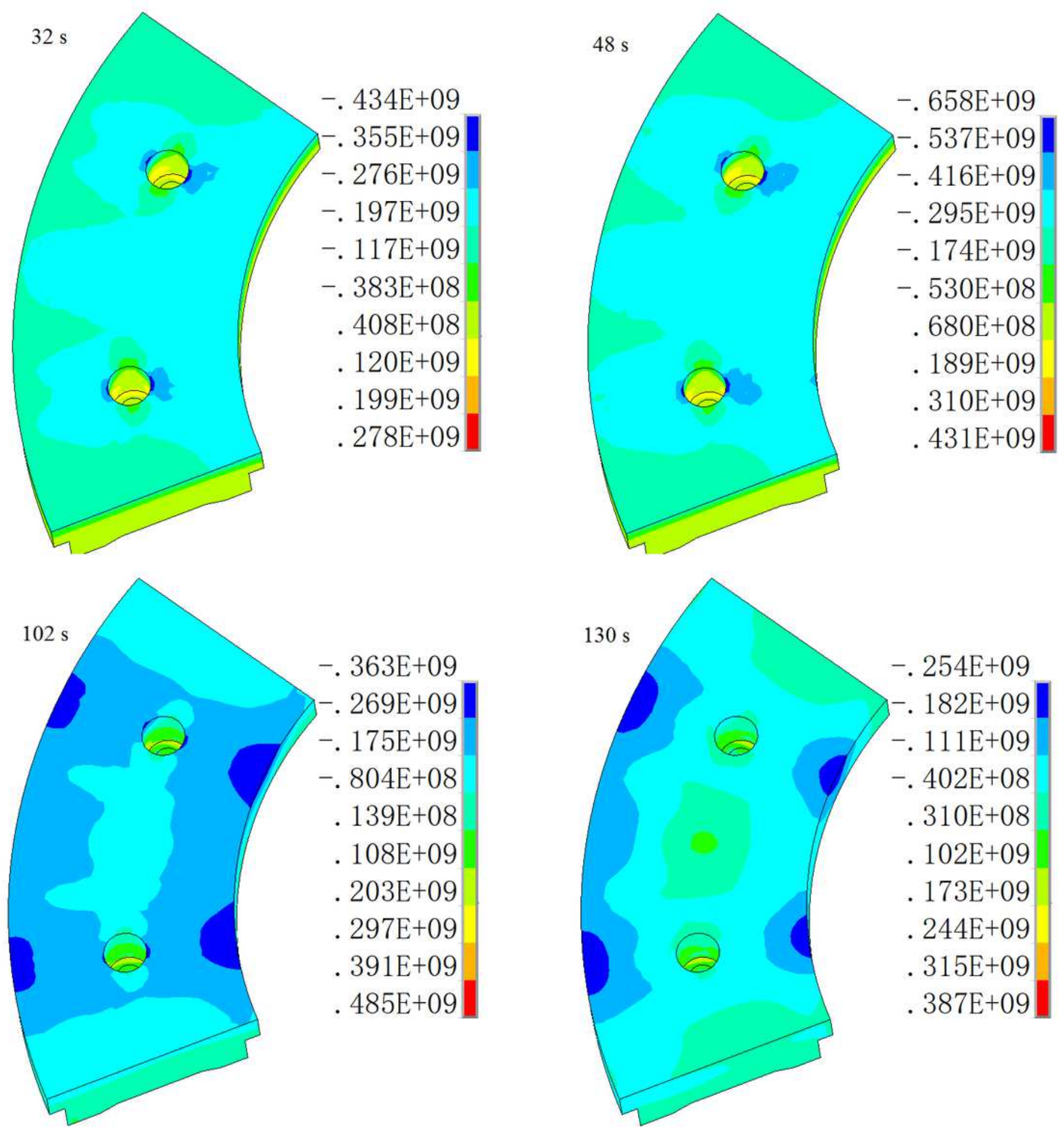

Figure 10

Circumferential stress contour of brake disc 


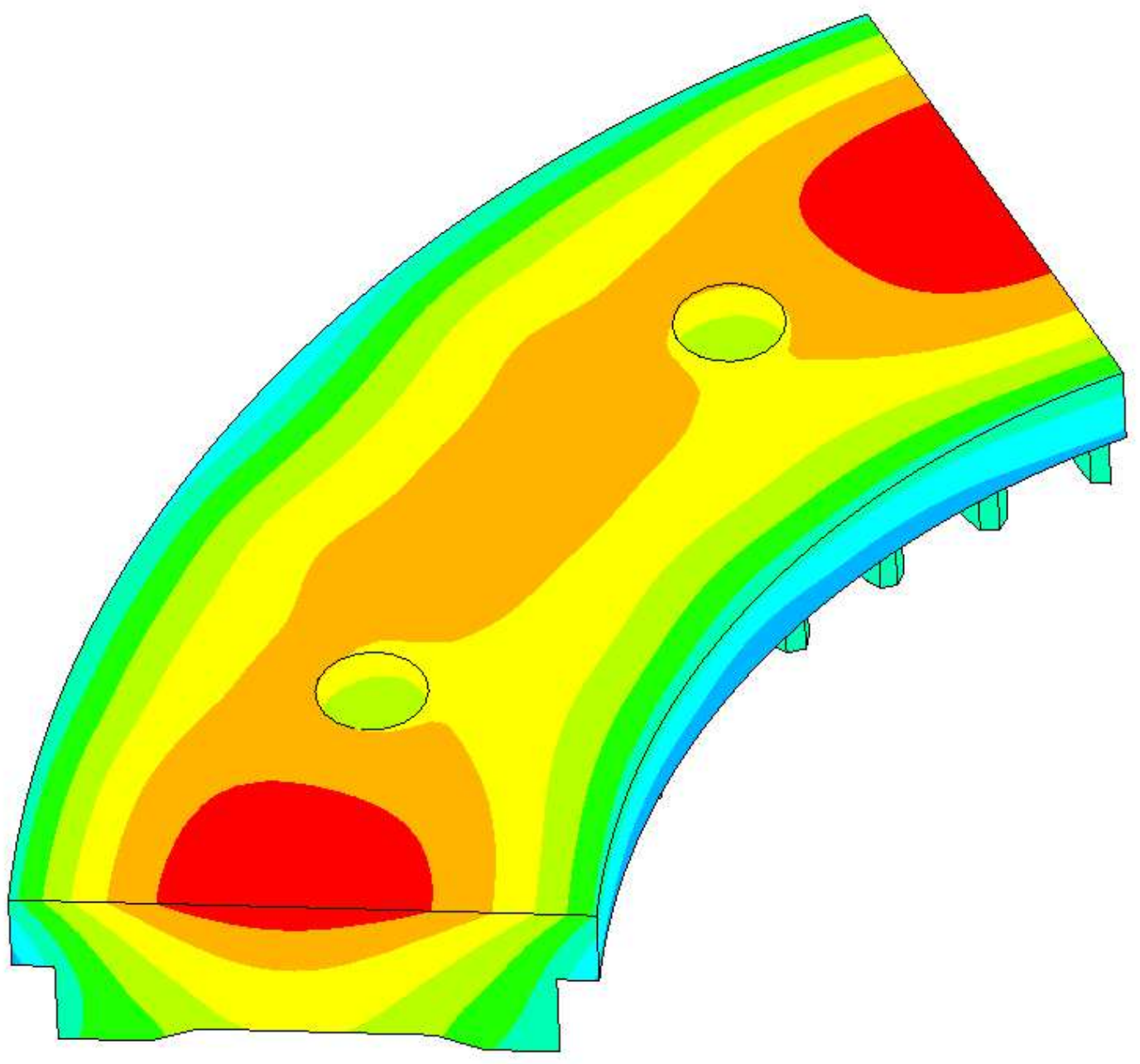

-. $994 \mathrm{E}-04$

-. 687E-04

-. $380 \mathrm{E}-04$

-. $726 \mathrm{E}-05$

$.235 \mathrm{E}-04$

$.542 \mathrm{E}-04$

$.849 \mathrm{E}-04$

$.116 \mathrm{E}-03$

. $146 \mathrm{E}-03$

$.177 \mathrm{E}-03$

Figure 11

Axial deformation contour of brake disc 


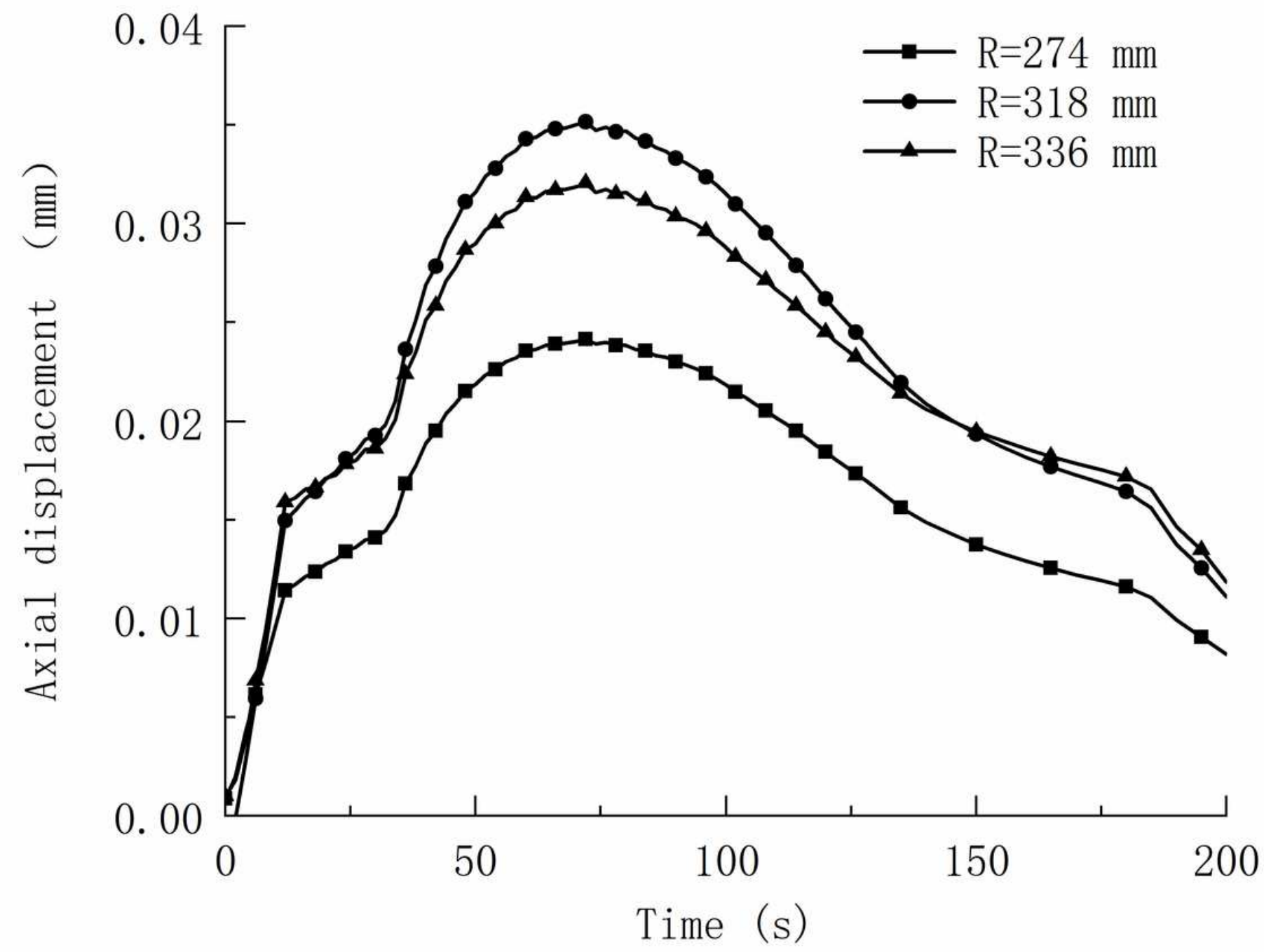

Figure 12

The axial displacement of the bolt hole on the contact surface of the disc body and the wheel changes with time 